\title{
USO DE DIFERENTES FONTES DE BIOMASSA VEGETAL PARA PRODUÇÃO DE BIOCOMBUSTÍVEIS SÓLIDOS
}

\author{
S. R. L. TAVARES ${ }^{1}$ e T. E. SANTOS ${ }^{2}$ \\ ${ }^{1}$ Empresa Brasileira de Pesquisa Agropecuária (EMBRAPA SOLOS) \\ ${ }^{2}$ Universidade Federal do Rio de Janeiro (Escola de Química/UFRJ) \\ E-mail: silvio.tavares@embrapa.br ${ }^{1}$
}

Artigo submetido em novembro/2013 e aceito em dezembro/2013

\section{RESUMO}

Entre as várias fontes para produção de energia, a biomassa vegetal apresenta um grande potencial de crescimento nos próximos anos. O objetivo deste estudo foi a avaliação das propriedades físicas, químicas e energéticas de algumas biomassas agrícolas plantadas (capim elefante e capim vertiver); biomassa disponível em corpos hídricos superficiais (macrófita) e biomassas advindas de explorações florestais (carnaúba e palmeira real), para a produção de briquetes visando a utilização deste combustível sólido nas cerâmicas vermelhas estruturais na região do baixo-açu no Rio Grande do Norte. O delineamento experimental utilizado foi inteiramente casualizado (DIC) com 3 repetições para cada espécie investigada., totalizando 15 parcelas experimentais ( 5 biomassas $X 3$ repetições).
Foram analisados também as densidades e o Poder Calorífico Superior de diferentes composições (blends) de capim elefante e palha de carnaúba. Os resultados mostram que os briquetes oriundos das biomassas vegetais como palha de carnaúba e capim elefante, apresentam grandes potenciais para o uso na geração de energia térmica nos fornos existentes das cerâmicas da região e que essas biomassas podem ser utilizadas na fabricação de briquetes, tanto de forma individual, como misturadas em blends de diferentes composições, visando a manutenção de fabricação de briquetes ao longo de todo o ano agrícola apresentando uma maior regularidade das características físico-térmicas dos mesmos.

PALAVRAS-CHAVE: briquete, energia renovável, bioenergia

\section{USE OF DIFFERENT SOURCES OF BIOMASS PLANT FOR THE PRODUCTION OF SOLID BIOFUEL}

\begin{abstract}
Among the various sources for energy production, plant biomass has great potential for growth in coming years. The objective of this study was to evaluation the physical, chemical and energetic properties of some agricultural biomass planted (elephant grass and vertiver grass) ; biomass available in surface water bodies (macrophyte) and resulting biomass of forest holdings (real palm and carnauba straw), to production of briquettes in order to use this solid fuel in structural red ceramics in the baixo-açu region in Rio Grande do Norte . The experimental design was completely randomized (CRD) with 3 replications for each species investigated. Totaling 15 experimental plots (5
\end{abstract}

biomasses $X 3$ repetitions). Superior Carorific Power and densities of different compositions ( blends ) of elephant grass and carnauba straw were also analyzed. The results show that the briquettes plant derived biomass as carnauba straw and elephant grass, have great potential for use in thermal power generation in existing ceramic kilns in the region and that the biomass can be used in the manufacture of briquettes, both individually, as in mixed blends of different compositions, in order to maintain the manufacture of briquettes throughout the growing season with a greater regularity of physical and thermal characteristics.

KEYWORDS: briquette, renewable energy, bioenergy 


\section{USO DE DIFERENTES FONTES DE BIOMASSA VEGETAL PARA PRODUÇÃO DE BIOCOMBUSTÍVEIS SÓLIDOS}

\section{INTRODUÇÃO}

Estima-se atualmente que a biomassa represente cerca de $14 \%$ de todo o consumo mundial de energia primária. Em alguns países em desenvolvimento, esta parcela pode aumentar para 34\%, chegando a 60\% na África (IPCC, 2011). No Rio Grande do Norte, estima-se este percentual em 33,4\% do consumo total de energia primária. Deste percentual, o consumo de lenha e carvão representa mais de $2 / 3(24,2 \%)$. Os setores: residencial, industrial e de serviços consomem quase $50 \%$ de sua demanda de energia através do uso de lenha e carvão vegetal (RIO GRANDE DO NORTE, SEDEC, 2006).

A utilização de florestas como fonte de energia é tão antiga quanto a história da humanidade. Desde os primórdios da história da civilização, a vegetação se constituiu como uma fonte energética, sendo utilizada em atividades domésticas e, posteriormente, em atividades manufatureiras e industriais. O Rio Grande do Norte apresenta um quadro de forte dependência social e econômica em relação ao recurso florestal, principalmente nas micro-regiões (como as do Seridó e Baixo-Açu) que possuem parques industriais cerâmicos. A biomassa oriunda, na sua maior parte de matas nativas, fornece energia para 35\% do parque industrial do Estado e é a sua segunda fonte de energia com uma participação de $30 \%$ da sua matriz energética. Contudo, a exploração florestal com essa finalidade ainda utiliza-se de técnicas extremamente rudimentares que proporciona uma pressão sobre o meio-ambiente, afetando diretamente as espécies vivas que habitam esses espaços. Convém destacar que o desmatamento acelerado da caatinga coloca em risco a sua biodiversidade e a sobrevivência de camadas da população que dependem do potencial de seus recursos naturais para sobreviverem.

Diante deste quadro, a implementação e difusão de tecnologias de adensamento lignocelulósico (briquete) em substituição ao uso da lenha nativa visando a redução significativa do desmatamento do bioma caatinga na microrregião do baixo Açu através da exploração de biomassa agrícola para fins energéticos e extrativismo florestal sustentável, surge como uma alternativa concreta para o fornecimento aos consumidores da região de biocombustíveis sólidos para geração de calor em seus processos industriais.

Briquete é uma peça sólida de biomassa comprimida com uma carga média de $6 \mathrm{tf}$ a $8 \mathrm{tf}$ (tensão de 90 a $140 \mathrm{~kg} / \mathrm{cm} 2$ ), gerando uma temperatura de 170 a $270^{\circ} \mathrm{C}$ em uma câmara de briquetagem visando a decomposição parcial da lignina, apresentando teor de umidade na base úmida de 5 a 15\%, sendo o ótimo $8 \%$, com ou sem aglutinante, com uma densidade entre 1,0 a $1,5 \mathrm{t} / \mathrm{m} 3$, apresentando peças cilindricas ou hexagonais entre 70 a $100 \mathrm{~mm}$ e comprimento e $10 \mathrm{a}$ $40 \mathrm{~cm}$ (GENTIL, 2008).

Para a produção econômica de briquetes é necessário a seleção de biomassas vegetais que comporão os mesmos e que possuam determinadas características que os tornem aptos para a geração de energia térmica. Dessas características, o poder calorífico e algumas propriedades físicas e químicas (composição química elementar e imediata); teor de umidade; poder calorífico superior, inferior e líquido; granulometria; teor de cinzas, etc., tem influência direta sobre a viabilidade do uso do material como combustível. 
Segundo Ferreira et al. (2012), a utilização dos resíduos como fonte de energia através de sua densificação, compactação ou aglomeração proporciona uma série de vantagens, quando comparada a sua utilização em estado natural, principalmente no tocante ao armazenamento, manuseio, aumento de densidade e poder calorífico. A taxa de combustão é comparavel à do carvão, sendo que a combustão é mais uniforme, com redução da emissão de partículas e maior inflamabilidade. As dimensões dos briquetes uniformes e padronizados garantem um menor custo de transporte e fácil armazenamento. As características do briquete apresentando baixa umidade media, associado a um baixo teor de cinzas (inferior a $2 \%$ ) e elevado poder calorífico (entre 4.500 e 5.000 quilocalorias por quilograma), faz com esse esses biocombustível mostre grande viabilidade técnica para uso principalemnte em fornos de queima e caldeiras. De maneira geral, a qualidade dos briquetes geralmente é determinada pelo tipo de material in natura, ligante utilizado e a precisão com que as operações relacionadas à briquetagem são realizadas.

Diante do exposto, o trabalho teve como objetivo a avaliação das propriedades energéticas de biomassas agrícolas plantadas (capim elefante e vertiver); macrófita e biomassas advindo de explorações florestais (carnaúba e palmeira real), para a produção de briquetes.

\section{MATERIAIS E MÉTODOS}

As biomassas analisadas referem-se as gramíneas: capim elefante (Pennisetum purpureum) e capim vetiver (Vetiveria zizanioides), as palmeiras: carnaúba (Copernicia prunifera) e palmeira real (Archontophoenix Alexandrae) e a macrófita conhecida como aguapé (Eichhornia crassipes). Essas espécies podem ser plantadas e/ou exploradas na região de estudo (Vale do Açu, RN). Foram analisadas no experimento as partes aéreas dos capins e macrófita (folhas e caules), o tronco da palmeira real e os resíduos de folhas de carnaúba após a extração da cera. As análises foram realizadas nos laboratórios das Embrapas : Solos (RJ), Tecnologia de Alimentos (RJ), Agrobiologia (RJ) e Floresta (PR) e nos laboratórios da REDUC/PETROBRAS (RJ).

As propriedades físicas, químicas e térmicas dos materiais lignocelulósicos utilizados foram analisados visando obter um aproveitamento mais eficiente de suas propriedades, visando a produção de briquetes. As propriedades analisadas foram: Composição química elementar (Carbono; Hidrogênio e Nitrogênio); Composição química imediata (Umidade; Materiais voláteis; Carbono fixo e Cinzas); Fibra em Detergente Ácido (FDA); Lignina; Celulose; Sílica; Fibra em Detergente Neutro (FDN); Densidade e Poder Calorífico Superior (PCS).

O delineamento experimental utilizado foi inteiramente casualizado (DIC) consistindo na análise para determinar a qualidade da biomassa de cinco diferentes espécies vegetais para uso como combustível térmico em fornos de produção de cerâmica vermelha, totalizando 15 parcelas experimentais ( 5 biomassas $X 3$ repetições). Desta forma, os resultados aferidos das análises realizadas nas amostras das biomassas foram organizadas em planilhas eletrônicas e, em seguida, calculados os resíduos utilizando o software SAS e executados os testes de homogeinidade de variância, segundo os métodos de Cochran/Bartlet e normalidade pelo teste de Lilliefors, por meio do software SAEG 9.1. Em sequência, foi realizada a análise de variância nos dados utilizando o software SISVAR versão 5.1 e aplicado o teste de comparação de médias (Tukey a 5\% de probabilidade).

Os ensaios iniciais foram realizados nas matérias primas sem terem sofridas o processo de briquetagem. Já a densidade e PCS foram realizadas nas biomassas briquetadas. 


\section{Caracterização das materias primas (biomassas)}

As quantificações de teor de umidade, cinzas, materiais voláteis e carbono fixo foram realizadas no equipamento TGA-2000, de acordo com a NBR 8112 OUT/1986. A análise consiste em pesar 0,5 g de cada amostra, colocá-la no cadinho apropriado do próprio equipamento e ajustar a programação desejada.

A quantificação de $\mathrm{C} \mathrm{H} \mathrm{N}$ elementar foi realizada no Analisador de $\mathrm{CHN}$ da Perkin Elmer ${ }^{\circledR}$, modelo 2400.

As quantificações de FDA, lignina, celulose, cinzas, sílica e FDN foram feitas no Laboratório de Leguminosas da Embrapa Agrobiologia de acordo com a metodologia descrita por Silva, 1990.

$$
\begin{aligned}
& \text { \% FDA }=\text { (peso FDA }- \text { peso do cadinho vazio })^{*} 100 / \text { peso da amostra } \\
& \% \text { FDN }=[100-(\text { peso da amostra }- \text { peso do resíduo })]^{*} 100 / \text { peso da amostra } \\
& \% \text { Cinzas }=(\text { peso das cinzas })^{*} 100 / \text { peso da amostra } \\
& \% \text { Lignina }=\text { (peso FDA }- \text { peso do cadinho + celulose }+ \text { cinzas })^{*} 100 / \text { peso da amostra } \\
& \% \text { Celulose }=[(\text { peso do cadinho }+ \text { cellulose }+ \text { cinzas })-(\text { peso do cadinho }+ \text { cinzas })]^{*} 100 / \\
& \text { peso da amostra }
\end{aligned}
$$

\section{Confecção dos briquetes}

As amostras para briquetagem foram secas em estufa de circulação forçada a $65^{\circ} \mathrm{C}$ durante cerca de 8 horas. $O$ volume de cada material, antes de ser briquetado, ficou em torno de $500 \mathrm{ml}$ e média de $45 \mathrm{~g}$. A briquetadeira utilizada neste estudo foi da marca Lippel $^{\circledR}$, modelo LB 32, a pressão empregada foi de 95 Bar (9902 kgf) e temperatura de $120^{\circ} \mathrm{C}$. Cada amostra foi submetida a briquetagem por 5 minutos e 3 minutos para resfriamento.

\section{Densidade dos briquetes}

Depois de sofrer o processo de briquetagem foi analisada uma das mais importantes características do produto, a sua densidade relativa aparente por meio do método estequiométrico que consiste em obter o volume a partir de medições, utilizando-se um paquímetro e uma balança com precisão de $5 \mathrm{mg}$. A densidade dos briquetes foi calculada a partir das medidas do volume e da massa dos briquetes.

\section{Poder Calorífico Superior}

As análises do Poder Calorífico de cada briquete foram realizadas no Calorímetro C-5003 da IKA, pertencente à Embrapa Florestas, de acordo com a NBR 8333/84 e as normas NBR 5734 e NBR 6923.

\section{RESULTADOS E DISCUSSÃO}

\section{Composição Química Elementar (CQE)}


A composição química elementar $(\mathrm{C} ; \mathrm{H} ; \mathrm{N} ; \mathrm{S} ; \mathrm{O}$ e cinzas) corresponde ao conteúdo percentual em massa dos principais elementos que constituem a biomassa, geralmente referente a matéria seca, ou seja, sem considerar a presença da água. Considerando-se as substâncias que constituem a parede celular das plantas, é importante ressaltar que a lignina é rica em carbono e hidrogênio, que são os elementos que produzem calor e portanto têm mais poder calorífico que a celulose. Por este motivo, é muito importante conhecer os teores de lignina e celulose das biomassas que em muitos casos são facilmente modificados pelo manejo cultural ou pela blendagem com materiais mais ricos em componentes orgânicos que aumentem o PCS das misturas e o tempo de queima do biocombustível sólido proposto.

Tabela 1 - Composição Química Elementar (CQE) das biomassas isoladas:

\begin{tabular}{|c|c|c|c|c|c|c|}
\hline $\begin{array}{c}\text { Fonte de } \\
\text { Variação }\end{array}$ & $\begin{array}{c}\mathrm{C}^{* *} \\
(\%)\end{array}$ & $\begin{array}{c}\mathrm{H}^{* *} \\
(\%)\end{array}$ & $\begin{array}{c}\mathrm{N}^{* *} \\
(\%)\end{array}$ & $\begin{array}{c}\text { Lignina } \\
(\%)\end{array}$ & $\begin{array}{c}\text { Celulose } \\
(\%)\end{array}$ & $\begin{array}{c}\text { Sílica } \\
(\%)\end{array}$ \\
\hline $\mathrm{PC}^{*}$ & $40,40 \mathrm{a}$ & $5,61 \mathrm{a}$ & $1,72 \mathrm{a}$ & $20,33 \mathrm{~b}$ & $10,38 \mathrm{c}$ & $14,42 \mathrm{~b}$ \\
\hline $\mathrm{CE}^{*}$ & $39,34 \mathrm{a}$ & $5,48 \mathrm{a}$ & $0,87 \mathrm{c}$ & $13,85 \mathrm{c}$ & $15,82 \mathrm{~b}$ & $13,54 \mathrm{~b}$ \\
\hline $\mathrm{CV}^{*}$ & $39,55 \mathrm{a}$ & $5,54 \mathrm{a}$ & $0,46 \mathrm{~d}$ & $11,59 \mathrm{c}$ & $20,85 \mathrm{a}$ & $13,29 \mathrm{~b}$ \\
\hline $\mathrm{M}^{*}$ & $31,08 \mathrm{~b}$ & $4,69 \mathrm{~b}$ & $1,28 \mathrm{~b}$ & $26,87 \mathrm{a}$ & $3,50 \mathrm{~d}$ & $23,37 \mathrm{a}$ \\
\hline $\mathrm{PR}^{*}$ & $39,34 \mathrm{a}$ & $5,88 \mathrm{a}$ & $0,31 \mathrm{~d}$ & $17,58 \mathrm{~b}$ & $15,06 \mathrm{~b}$ & $11,01 \mathrm{~b}$ \\
\hline
\end{tabular}

OBS: Médias seguidas pela mesma letra na coluna não diferem significativamente pelo Teste de Médias de Tukey, ao nível de $5 \%$.

* PC (palha de Carnaúba); CE (Capim Elefante); CV (Capim Vertiver); M (Macrófita) e PR (Palmeira Real).

** C (Carbono); H (Hidrogênio) e N (Nitrogênio).

A biomassa da macrófita apresentou o maior teor de lignina e o menor de celulose entre todos os tratamentos. Apesar da literatura mostrar que lignina têm maior poder calorífico do que a celulose $(5.995 \mathrm{kcal} / \mathrm{kg}$ contra $3.797 \mathrm{kcal} / \mathrm{kg}$, BRAND, 2010), outros fatores devem ser levados em consideração, e neste caso específico em relação aos elevados teores de lignina na macrófica, a mesma apresenta menos voláteis, carbono, hidrogênio, celulose, FDN, e PCS do que os demais tratamentos e mais cinzas, FDA, e sílica que a coloca na classificação de pior biomassa para ser utilizada com fins energéticos neste trabalho.

O elevado teor de lignina na palha de carnaúba, aliada com outros bons parâmetros de CQE nesta biomassa, a coloca como a melhor biomassa, em termos gerais, dos tratamentos estudados. Um possível conteúdo de resíduos de cera de carnaúba (pó cerífero) remanescente das operações de retirada dos mesmos no campo, pode ser o responsável por este maior valor de lignina encontrada neste tratamento. É importante ressaltar que a lignina é um polímero termoplástico sendo então o principal composto que atua como aglomerante das partículas de biomassa na fabricação de briquetes. Segundo PAULRUD (2004), o processo de fabricação de briquetes utilizando elevadas pressões no processo, leva a plastificação da lignina entre 80 e $200^{\circ}$ $\mathrm{C}$, dependendo do tipo de material ligno-celulósico. Esse polímero depois de resfriado, promove a colagem das partículas adensadas. A lignina solidificada na superfície faz com que o briquete resista à umidade, justificando a não utilização de produtos aglomerantes como cola, resina, cera ou amido.

Em relação ao teor de sílica nas biomassas estudadas, a macrófita apresentou os teores mais elevados (Tabela 1). Essa característica torna essa biomassa inapropriada para a briquetagem, uma vez que gerando maior atrito interno nos components da briquetadeira, acabe promovendo um maior desgaste das peças, e assim, reduzindo a vida útil da máquina (PEREIRA, 2006). 


\section{Composição Química Imediata (CQI)}

A composição química imediata se refere ao conteúdo percentual do carbono fixo, materiais voláteis, cinzas e eventualmente umidade, baseado na massa do combustível. 0 conteúdo de voláteis expressa a facilidade de se queimar o material e o carbono fixo o tempo de queima. Logo, pelo conhecimento desses dois índices percentuais, pode-se estimar o grau de combustão de uma biomassa e o tempo de queima da mesma, maximizando assim o desenho do projeto de obtenção de energia a partir de biomassas vegetais.

A biomassa com maior teor de voláteis e menor teor de cinzas apresenta, normalmente, maior poder calorífico. Este fato foi evidenciado com os resultados apresentados na tabela 2 para a biomassa de Palmeira Real (maior PCS), bem como para a macrófita (menor PCS), devido a relação inversa: menor teor de voláteis e maior teor de cinzas.

Tabela 2 - Composição Química Imediata (CQI), FDA e FDN das biomassas isoladas:

\begin{tabular}{|c|c|c|c|c|c|c|}
\hline $\begin{array}{c}\text { Fonte de } \\
\text { Variação }\end{array}$ & $\begin{array}{c}\text { Umidade } \\
(\%)\end{array}$ & $\begin{array}{c}\text { Voláteis } \\
(\%)\end{array}$ & $\begin{array}{c}\text { Cinzas } \\
(\%)\end{array}$ & $\begin{array}{c}\mathrm{CF}^{* *}=100- \\
(\mathrm{CZ}+\mathrm{MZ})\end{array}$ & $\begin{array}{c}\text { FDA } \\
(\%)\end{array}$ & $\begin{array}{c}\text { FDN } \\
(\%)\end{array}$ \\
\hline $\mathrm{PC}^{*}$ & $9,98 \mathrm{~b}$ & $89,42 \mathrm{~b}$ & $9,74 \mathrm{~b}$ & $0,89 \mathrm{~b}$ & $45,90 \mathrm{~b}$ & $60,23 \mathrm{~b}$ \\
\hline $\mathrm{CE}^{*}$ & $9,73 \mathrm{~b}$ & $89,90 \mathrm{~b}$ & $9,40 \mathrm{~b}$ & $0,70 \mathrm{~b}$ & $44,33 \mathrm{~b}$ & $71,30 \mathrm{a}$ \\
\hline $\mathrm{CV}^{*}$ & $8,89 \mathrm{~d}$ & $90,59 \mathrm{~b}$ & $8,76 \mathrm{~b}$ & $0,71 \mathrm{~b}$ & $45,84 \mathrm{~b}$ & $72,95 \mathrm{a}$ \\
\hline $\mathrm{M}^{*}$ & $9,48 \mathrm{c}$ & $67,65 \mathrm{c}$ & $29,67 \mathrm{a}$ & $2,78 \mathrm{a}$ & $54,77 \mathrm{a}$ & $54,53 \mathrm{c}$ \\
\hline $\mathrm{PR}^{*}$ & $11,12 \mathrm{a}$ & $93,77 \mathrm{a}$ & $6,03 \mathrm{c}$ & $0,21 \mathrm{c}$ & $44,66 \mathrm{~b}$ & $61,42 \mathrm{~b}$ \\
\hline
\end{tabular}

OBS: Médias seguidas pela mesma letra na coluna não diferem significativamente pelo Teste de Médias de Tukey, ao nível de $5 \%$.

* PC (palha de Carnaúba); CE (Capim Elefante); CV (Capim Vertiver); M (Macrófita) e PR (Palmeira Real).

** CF (Carbono Fixo); FDA (Fibra em Detergente Ácido) e FDN (Fibra em Detergente Neutro).

De uma maneira geral, os resultados encontrados para o carbono fixo em todos os tratamentos, apresentaram valores menores do que os confrontados em outros trabalhos. Este fato pode ter ocorrido pelo não uso de mesmos protocolos analíticos entre diferentes autores que trabalham com essas biomassas no Brasil. Isto leva a uma necessidade urgente de se uniformizar procedimentos de análises de biomassas para fins energéticos (produção de briquetes e pellets), pois os protocolos disponíveis e citados na literatura são referentes, na sua grande maioria, para análises de carvãos vegetal e mineral.

\section{Poder Calorífico Superior (PCS)}

As biomassas vegetais necessitam ter determinadas características que as tornem aptas para a geração de energia. Sem dúvida, o poder calorífico superior, dentre essas características, é a propriedade mais importante para avaliar a viabilidade de uso de uma biomassa na geração, principalmente de energia térmica.

A palha de carnaúba apresentou o maior PCS, seguido do capim elefante. O capim vertiver e a palmeira real não se diferenciaram entre si e a biomassa da macrófita foi o tratamento que apresentou o menor PCS. O poder calorífico superior está diretamente relacionado com o teor de carbono fixo e este, por sua vez, com os teores de materiais voláteis e cinzas (GENTIL, 2008). Levando em consideração estas relações, nota-se que, embora a biomassa da macrófita tenha apresentado o maior teor de carbono fixo, ao mesmo tempo, não manteve a relação esperada e teve os menores teores de voláteis e maiores teores de cinzas, colocando essa biomassa no menor índice de PCS. Outros fatores também influenciam o poder calorífico das biomassas. Entre 
eles, pode-se citar: a composição química; o tipo de biomassa e o teor de umidade. De acordo com a tabela 2, a composição química da palha de carnaúba e do capim elefante (no que se refere aos componentes de maiores contribuições ao PCS que são cellulose, lignin e fibras), são muito próximas, o que permite uma boa composição de blend para o uso dessas biomassas visando a produção de energia. O capim vertiver também tem de ser observado como boa alternativa as possíveis misturas com a palha de carnaúba ou mesmo com o capim elefante, já que o mesmo apresentou boas características nos parâmetros estudados (mesmo com menor teor de lignina), tendo suas análises, apreciadas no seu conjunto, mostrando a viabilidade prática do uso desta gramínea, principalmente por sua excelente plasticidade de adaptação e produção em diferentes condições edafo-climáticas e de manejo cultural.

FERREIRA, et al., 2012, encontraram o valor médio de $4.869 \mathrm{kcal} / \mathrm{kg}$ para a palha de carnaúba com o teor de umidade na base úmida de 5,2\% e o teor de cinzas também de 5,2\%. Como já comentado, o PCS é altamente influenciado pelos teores de umidade (uma vez que a quantidade de água livre na biomassa determina a quantidade de energia efetivamente disponível) e cinzas (que são compostas por todo o material que não queima, tornando-se resíduo no proceso de combustão). Cosiderando essas diferenças apresentadas entre este trabalho e desses autores, pode-se concluir que os resultados são aproximados.

Em relação ao PCS do capim elefante, BRAND, 2010, apresenta valores de PCS na faixa de 3.600 a $4.300 \mathrm{kcal} / \mathrm{kg}$; SARAIVA \& KONIG, 2013 (4.130 kcal $/ \mathrm{kg})$ e OLIVARES, 2002, apresentou o valor de $3.611 \mathrm{kcal} / \mathrm{kg}$ para o $\mathrm{PCl}$ (Poder Calorífico Inferior). Estes valores corroboram com os encontrados neste trabalho, já que em média, o PCl é em torno de 10 a $20 \%$ inferior ao PCS, colocando no mesmo nível, o resultado deste trabalho com o resultado encontrado pelo OLIVARES, 2002.

Tabela 3 - Poder Calorífico Superior (PCS) e Densidade das biomassas isoladas e do blend Capim Elefante (CE) X Palha de Carnaúba (PC):

\begin{tabular}{|c|c|c|c|c|c|}
\hline $\begin{array}{c}\text { Fonte de } \\
\text { Variação }\end{array}$ & $\begin{array}{c}\text { Densidade } \\
\left(\mathrm{g} / \mathrm{mm}^{3}\right)\end{array}$ & $\begin{array}{c}\text { P.C.S. } \\
(\mathrm{kcal} / \mathrm{kg})\end{array}$ & $\begin{array}{c}\text { Fonte de } \\
\text { Variação }\end{array}$ & $\begin{array}{c}\text { Densidade } \\
\left(\mathrm{g} / \mathrm{mm}^{3}\right)\end{array}$ & $\begin{array}{c}\text { P.C.S. } \\
(\mathrm{kcal} / \mathrm{kg})\end{array}$ \\
\hline $\mathrm{PC}^{*}$ & $2,57 \mathrm{~b}$ & $4.255,35 \mathrm{a}$ & $100 \%$ PC & 2,54 & 4.376 \\
\hline $\mathrm{CE}^{*}$ & $1,36 \mathrm{c}$ & $4.061,17 \mathrm{~b}$ & $90 \%$ PC e $10 \%$ CE & 2,43 & 4.356 \\
\hline $\mathrm{CV}^{*}$ & $2,22 \mathrm{~b}$ & $3.765,99 \mathrm{c}$ & $80 \%$ PC e $20 \%$ CE & 2,29 & 4.318 \\
\hline $\mathrm{M}^{*}$ & $2,50 \mathrm{~b}$ & $2.707,13 \mathrm{~d}$ & $70 \%$ PC e 30 \% CE & 2,21 & 4.315 \\
\hline $\mathrm{PR}^{*}$ & $3,90 \mathrm{a}$ & $3.678,01 \mathrm{c}$ & $60 \%$ PC e 40 \% CE & 2,05 & 4.334 \\
\hline- & - & - & $50 \%$ PC e 50 \% CE & 1,84 & 4.348 \\
\hline- & - & - & $40 \%$ PC e 60 \% CE & 1,76 & 4.332 \\
\hline- & - & - & $30 \%$ PC e 10 \% CE & 1,65 & 4.222 \\
\hline- & - & - & $20 \%$ PC e 70 \% CE & 1,55 & 4.175 \\
\hline- & - & - & $10 \%$ PC e 80 \% CE & 1,46 & 4.143 \\
\hline- & - & - & $100 \%$ CE & 1,34 & 4.176 \\
\hline
\end{tabular}

OBS: Médias seguidas pela mesma letra na coluna não diferem significativamente pelo Teste de Médias de Tukey, ao nível de $5 \%$. * PC (palha de Carnaúba); CE (Capim Elefante); CV (Capim Vertiver); M (Macrófita) e PR (Palmeira Real).

** CF (Carbono Fixo). 


\section{Densidade}

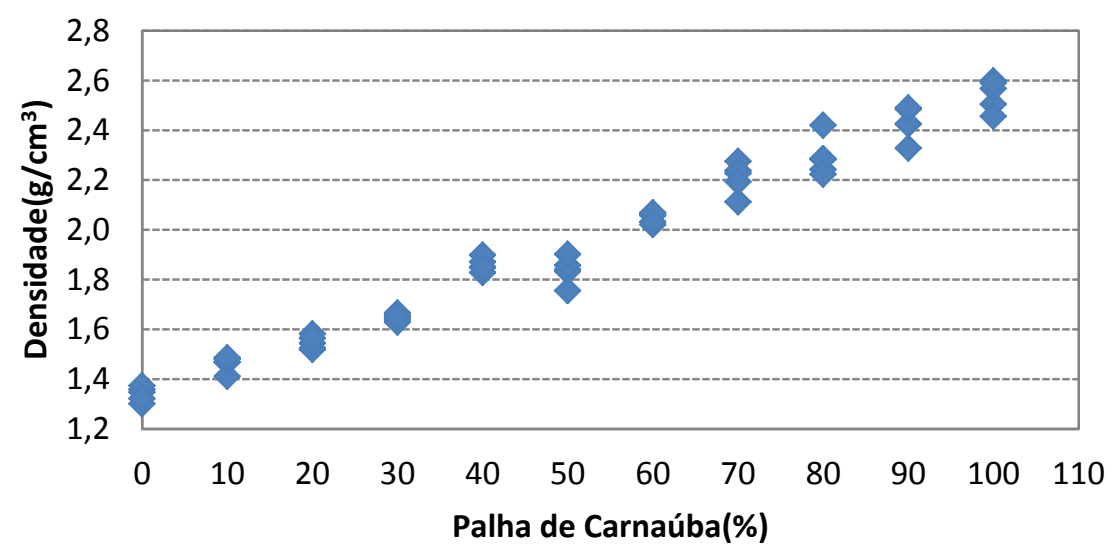

Figura 1 - Poder Calorífico Superior (PCS) X Densidade das biomassas blendadas com Capim Elefante (CE) X Palha de Carnaúba (PC).

As análises de densidade (Tabela 3 e Figura 1) corrabora com a maioria dos outros parâmetros analisados neste trabalho que mostra claramente que briquetes fabricados com $100 \%$ de palha de carnaúba gera um excelente produto final. Os parâmetros mais procurados pelo mercado energético de biomassa térmica (PCS e densidade) encontram-se nesta biomassa como a melhor opção para produção de um briquete comercialmente aceito como de classe 1. Além do mais, essa biomassa oriunda da exploração florestal na região do baixo-acu, já se encontra em seu estado de coleta de resíduo de produção de cera de carnaúba com umidade em torno de $10 \%$, se encontra também já fatiada pelas máquinas extratoras de cera com tamanho ideal para briquetagem, o que a coloca no ciclo produtivo (on farm) das fábricas, abortando duas importantes operacões: moagem e secagem. O gasto enegético na operação de moagem corresponde, em média a cerca de $70 \%$ dos custos energéticos total da produção industrial de briquetes.

\section{CONCLUSÕES}

Os briquetes oriundos das biomassas vegetais como palha de carnaúba, capim elefante e capim vertiver são potenciais para o uso na geração de energia;

As biomassas de palha de carnaúba e de capim elefante apresentaram as melhores características gerais referentes aos melhores parâmetros relacionados a fabricação de briquetes entre todos os tratamentos testados. Inclusive, essas biomassas podem ser utilizadas na fabricação de briquetes, tanto de forma individual, como misturadas em blendes de diferentes composições, visando a manutenção de fabricação de briquetes ao longo de todo o ano com uma regularidade nas características físico-térmicas dos mesmos;

Todas as biomassas estudadas apresentaram elevados teores de cinzas, o que indica que as mesmas não devem ser utilizadas em caldeiras para geração de energia elétrica, pois as mesmas podem causar danos, devido a formação de inscrustações de oxalato de cálcio na 
superfície das caldeiras. Diferentemente desta restrição, como a base de consumo de briquetes na região do baixo-açú no Rio Grande do Norte são cerâmicas vermelhas estruturais que utilizam fornos rudimentares, esses briquetes de palha de carnaúba e capim elefante são muito propícios ao uso devido aos mesmos apresentarem elevados PCS entre 4.061 e $4.255 \mathrm{kcal} / \mathrm{kg}$.

\section{REFERÊNCIAS BIBLIOGRÁFICAS}

1. BRAND, M. A. Energia de Biomassa vegetal. Interciência, Rio de Janeiro, 2010.

2. FERREIRA, J. C.; FURTADO, T. S.; VALIN, M.; BRAND, M. A. \& MUÑIZ, G. I. B. Potencialidade do uso de resíduos vegetais para a geração de energia através da técnica de briquetagem. BioMassa \& BioEnergia, edição 01, vol. 02., p. 18-25, 2012.

3. IPCC (Intergovernmental Panel on Climate Change): IPCC Special Report on Renewable Energy Sources and Climate Change Mitigation, 2011.

4. GENTIL, L. V. B. Tecnologia e economia de briquete de Madeira. Tese de doutorado. Pósgraduação em Ciências Florestais, EFL/FT/UnB, (Universidade Nacional de Brasília), 2008.

5. OLIVARES, G. E. Estudo da pirólise rápida de biomassa em leito fluidilizado borbulhante através da caracterização dos finos de carvão elutriados como etapa final à otimização do processo. Tese de doutorado., Universidade de campinas, UNICAMP, 2002.

6. PAULRUD, S. Upgraded Biofuels-Effects of Quality on Processing, Handling Characteristics, Combustion and Ash Melting. Doctoral Thesis. Swedish University of Agricultural Sciences. Sweden, 2004.

7. PEREIRA, M. Prevenção e manutenção de máquinas na Eco Industrial. Trabalho de graduação. Faculdade do Instituto Brasil. Anápolis, GO. 2006.

8. RIO GRANDE DO NORTE. Secretaria Extraordinária de Energia e Secretaria de Desenvolvimento Econômico (SEDEC). Balanço Energético do Estado do Rio Grande do Norte 2006. Natal, Rio Grande do Norte, 2006. 103 p. (Série Informações Energéticas, 1).

9. SARAIVA V.M. \& KONIG, A. Produtividade do capim-elefante-roxo irrigado com efluente doméstico tratado no semiárido potiguar e suas utilidades. Holos, ano 29, vol. 1., p. 28-46, 2013.250 